Site A
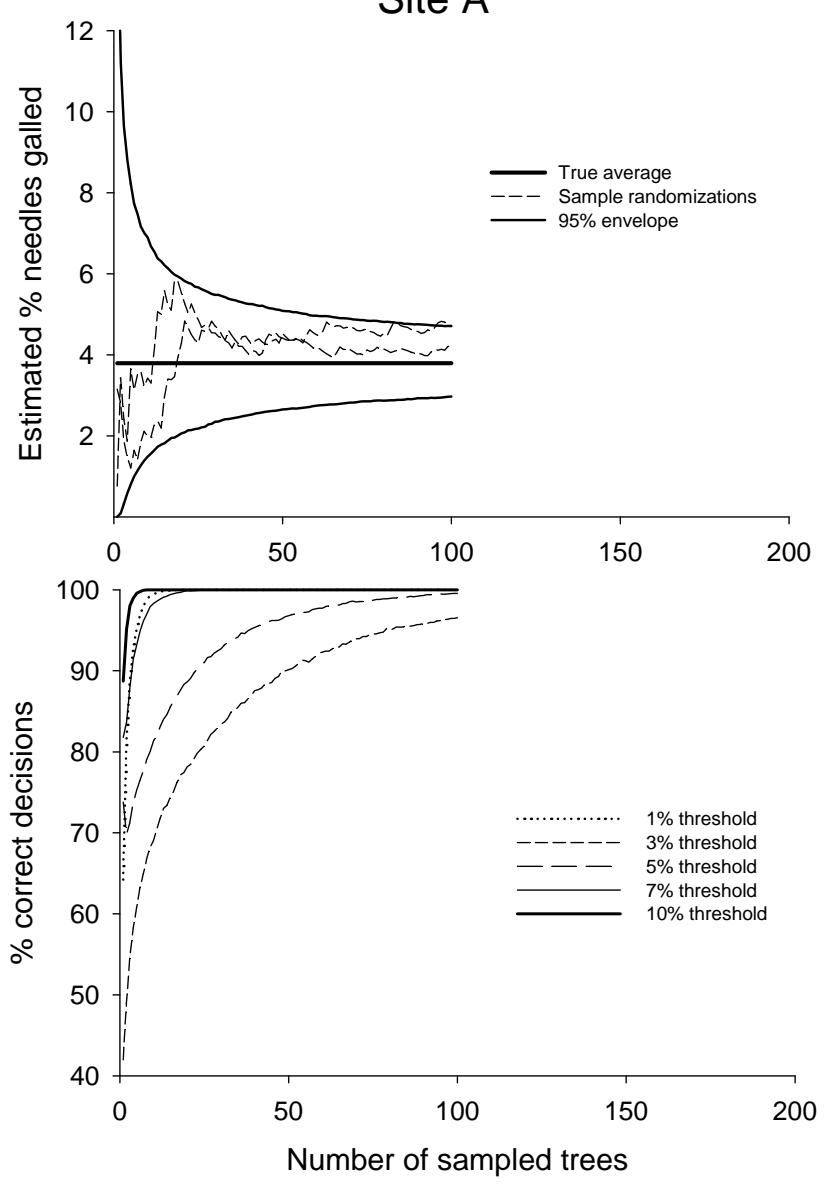

Site B
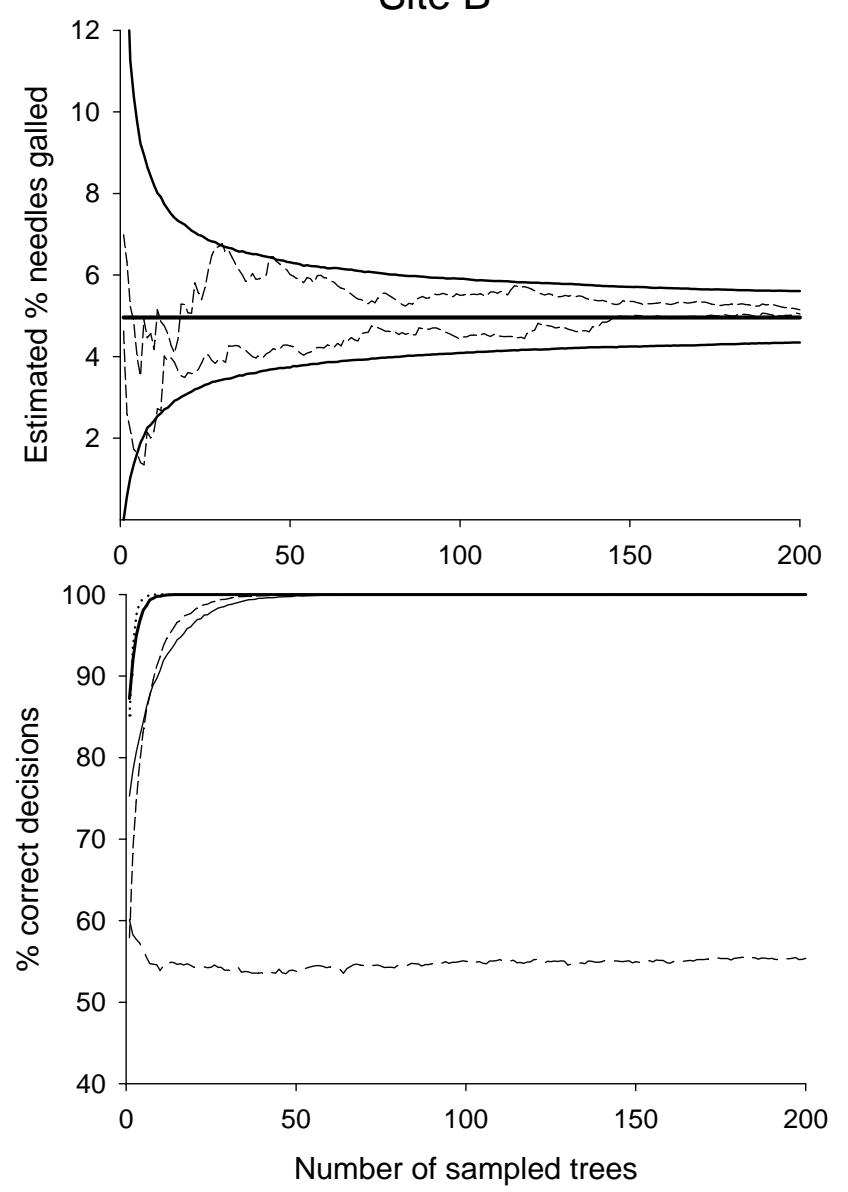

Figure S5. Performance of random sampling for estimating mean $P$. tumifex density (top panels) and decision-making against infestation thresholds (bottom panels) at all sites. Dashed lines show two representative randomizations; $95 \%$ of the 10,000 randomizations lie between the solid lines. Confidence envelopes still have finite width at $n=200$ (the size of the total site sample) because sampling is conducted with replacement. 
Site C
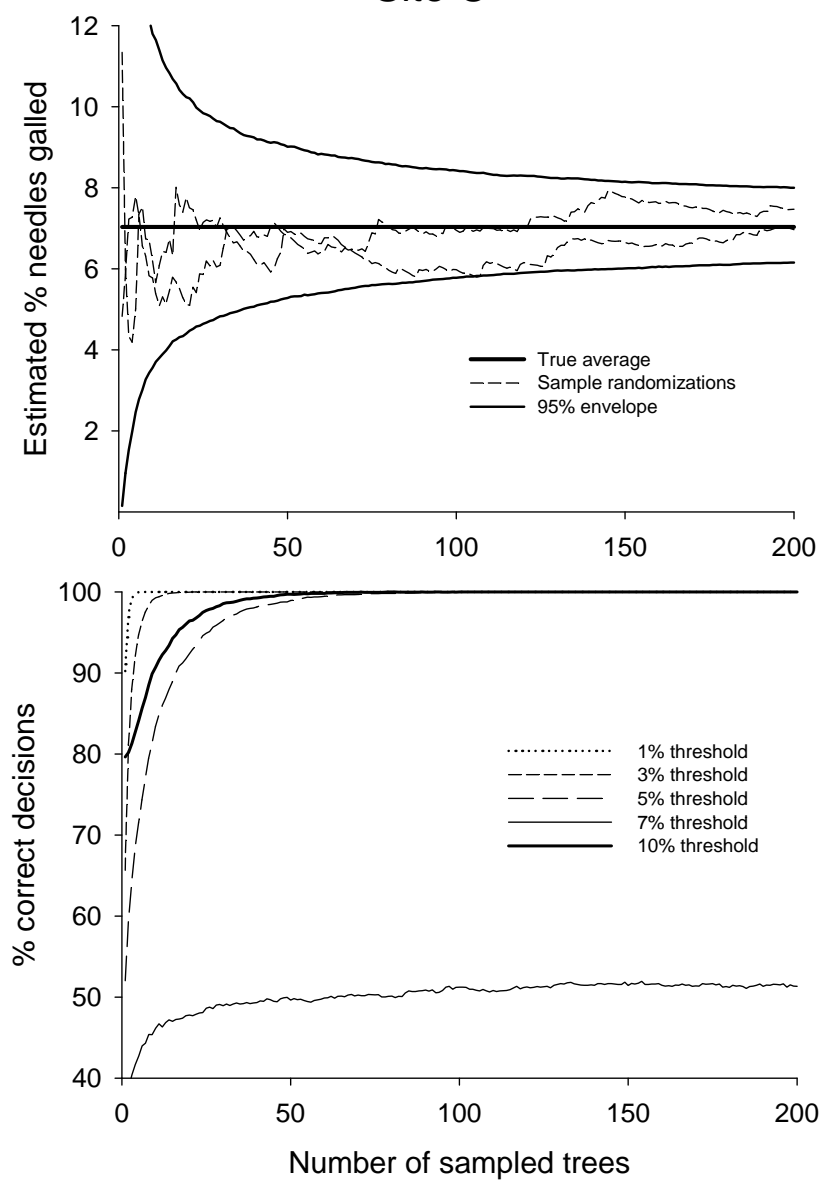

Site D
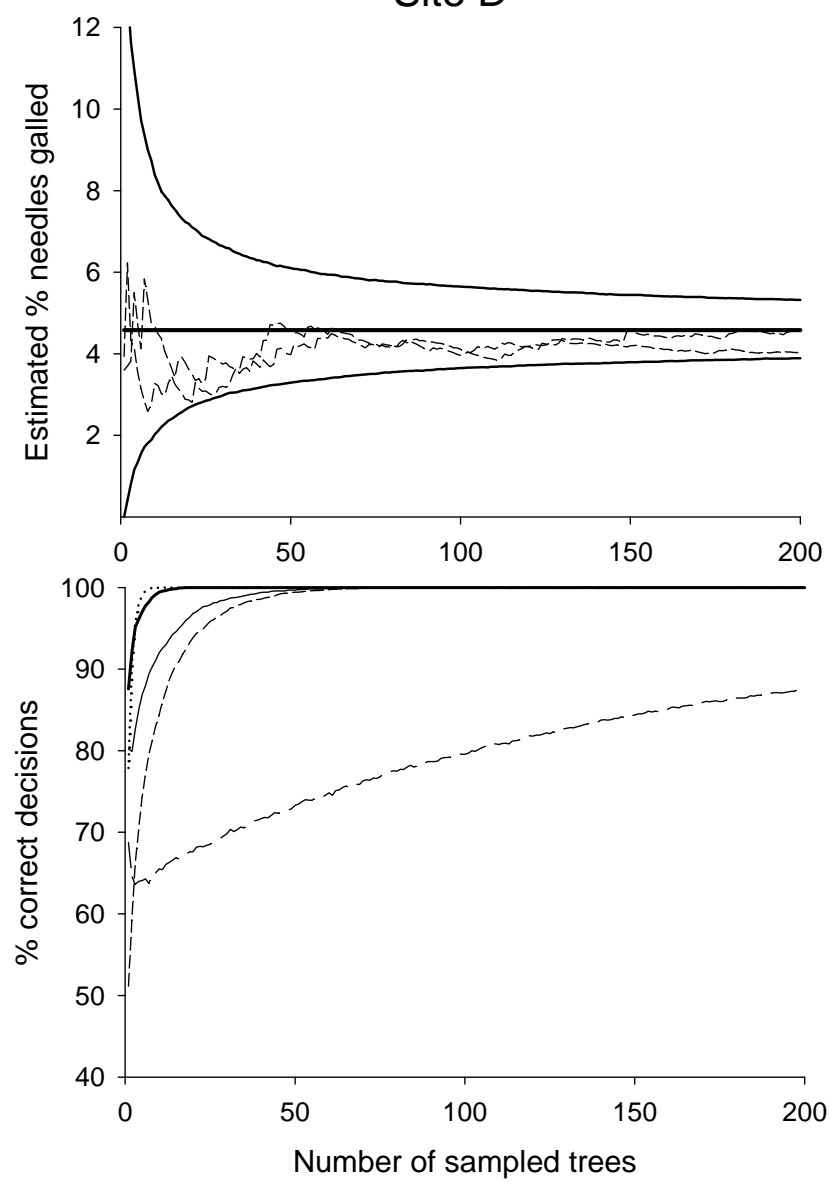

Figure S5. Performance of random sampling (continued). 

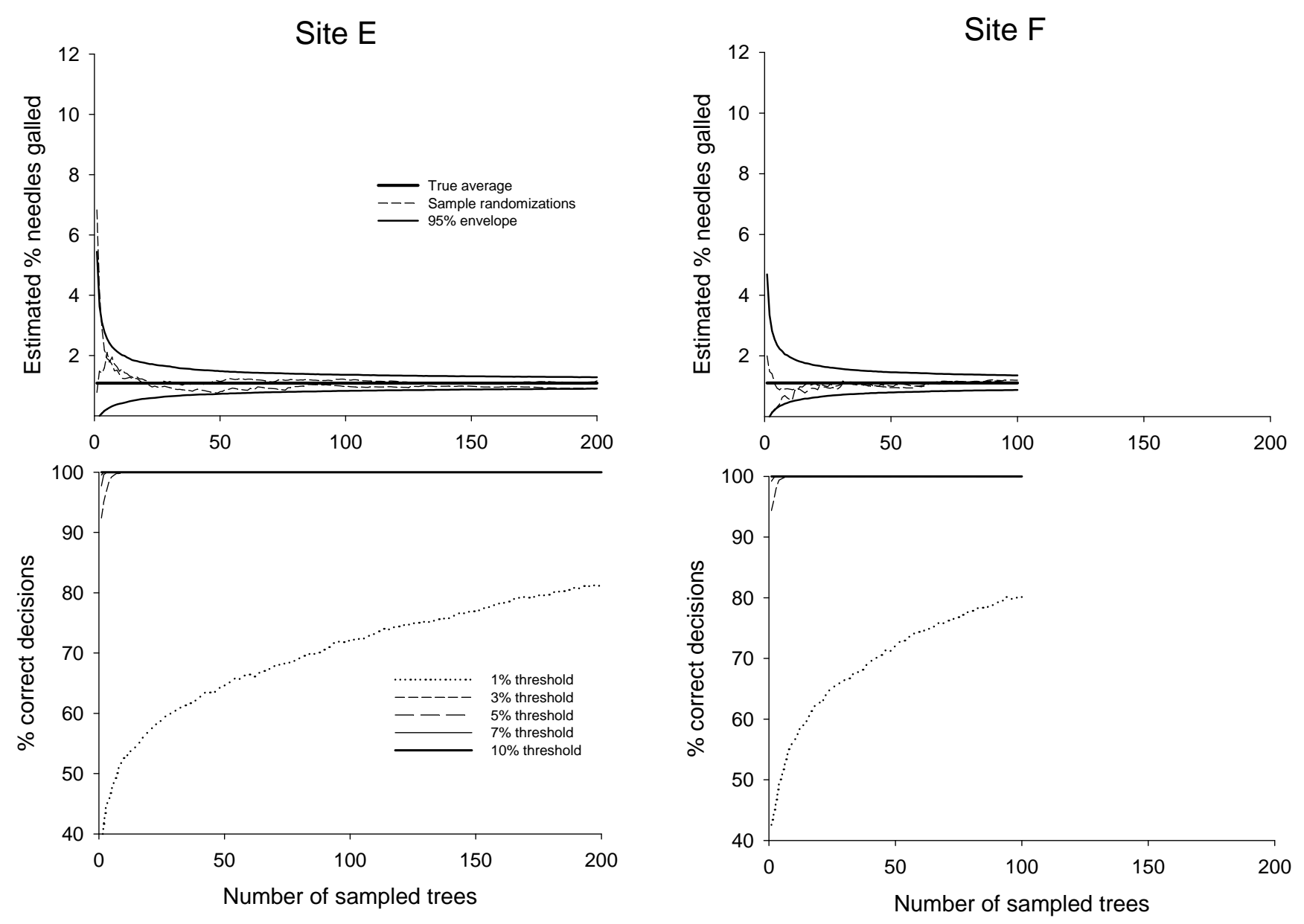

Figure S5. Performance of random sampling (continued). 


\section{Site G}

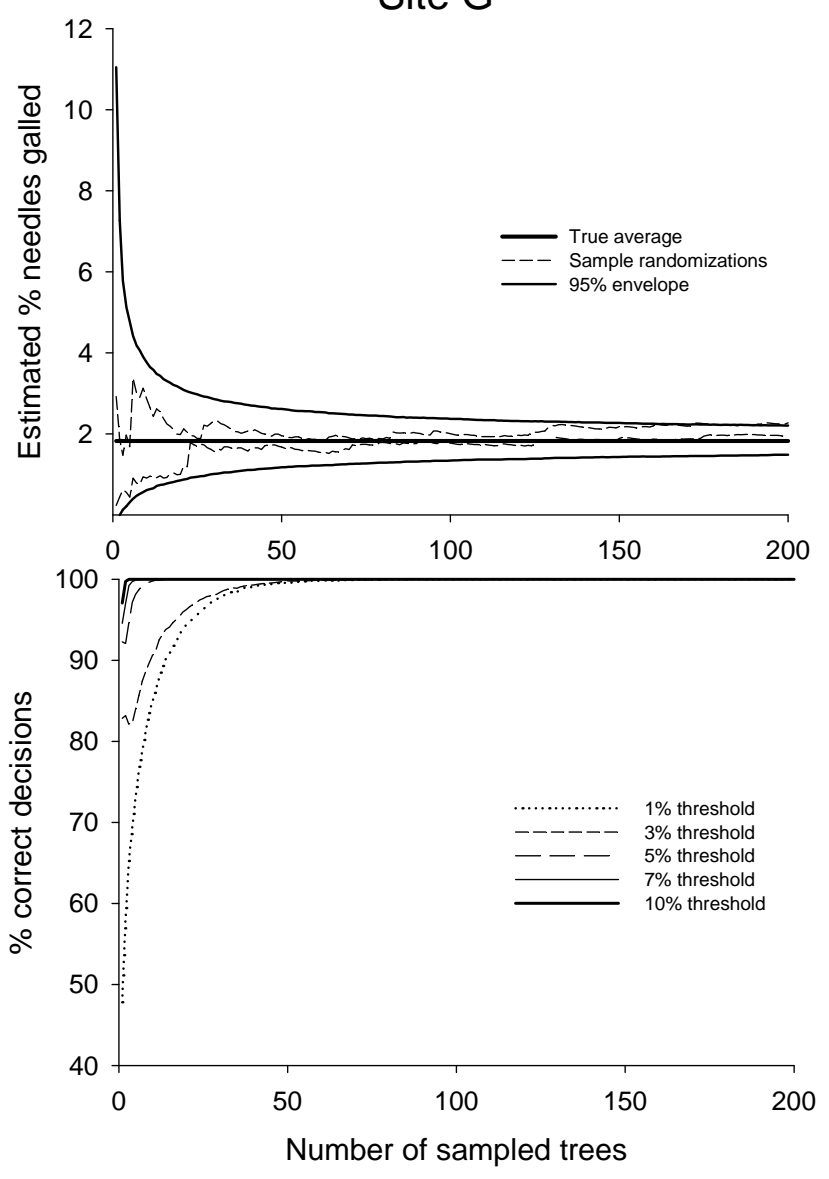

Figure S5. Performance of random sampling (continued). 